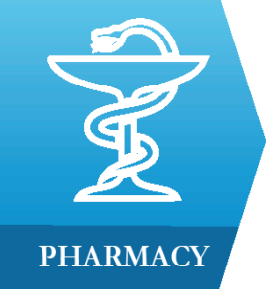

1) Toxicology Department, Iuliu Hatieganu University of Medicine and Pharmacy, Faculty of Pharmacy, ClujNapoca, Romania

2) Environmental Health Center, ClujNapoca, Romania
DOI: $10.15386 / \mathrm{mpr}-1742$

Manuscript received: 25.05 .2020

Accepted: 04.07.2020

Address for correspondence:

kbela@umfcluj.ro

This work is licensed under a Creative Commons Attribution-NonCommercialNoDerivatives 4.0 International License

\title{
Antibiotics in the environment: causes and consequences
}

Svetlana Iuliana Polianciuc ${ }^{1}$, Anca Elena Gurzău ${ }^{2}$, Bela Kiss ${ }^{1}$, Maria Georgia Ștefan ${ }^{1}$, Felicia Loghin ${ }^{1}$

\begin{abstract}
Antibiotics represent one of the main discoveries of the last century that changed the treatment of a large array of infections in a significant way. However, increased consumption has led to an exposure of bacterial communities and ecosystems to a large amount of antibiotic residues.

This paper aims to provide a brief overview of the primary drivers associated with antibiotic occurrence in the environment. Furthermore, we attempted to summarize the behavior of antibiotic residues in the environment and the necessity of their detection and quantification. Also, we provide updated scientific and regulatory facts about environmental antibiotic discharge and environmental and human antibiotics risk assessment.

We propose that environmental antibiotic contamination should be diminished beginning from regulating the causes of occurrence in the environment (such as antibiotic consumption) and ending with regulating antibiotic discharge and risk assessment. Some important intermediate steps are represented by the detection and quantification of the antibiotics and the characterization of their behavior in the environment, which could come to support future regulatory decisions.
\end{abstract}

Keywords: antibiotics, contamination, environment, risk assessment

\section{Introduction}

The emergence of antibiotic residues in the environment is a consequence of various patterns of antibiotic use, commonly directed towards fighting against bacterial infections and for livestock production [1]. Statistics show that consumption of antibiotics in animal husbandry is much higher than in human medicine. The first global (228 countries) map of antibiotic consumption in livestock published by Van Boeckel et al. provided a gross estimation of the total antibiotic consumption in 2010 (63,151 tons) and projected that antibiotic consumption will rise by $67 \%$ by 2030 and in some BRICS countries (Brazil, Russia, India, China, and South Africa) it will nearly double [2-5].

Antibiotics used in human and animal therapy are reaching the environment through urine and excreta, therefore optimizing and/or controlling the use of antibiotics are key elements in reducing environmental contamination. Between 40-90\% (depending on the class of drugs) of the administered antibiotic dose is excreted in the faeces and urine as parent compound - in the active form, eventually reaching the environment, contaminating soils, waters, plants, etc. The use of large amounts of antibiotics in animal farming can lead to agro-ecosystem contamination through the application of contaminated manure on the agricultural lands as fertilizer and the irrigation of crops with wastewater, among others. Another concern arises from the improper disposal of unused medicinal products by discharging them into the sewage systems. Antibiotic-contaminated wastewaters are treated in wastewater treatment plants (WWTP), but $100 \%$ removal of antibiotics is impossible in conventional WWTP. The sludge and final effluent from WWTP 
could contain antibiotics. Furthermore, the sludge could be used as manure fertilizer and the effluent is discharged into surface water [6-12].

Once in the environment, antibiotic residues can have negative effects on biota at different trophic levels, and on human health - by consumption of contaminated food and water, by the contribution to increasing the resistant bacterial population and maintaining selective pressure that causes the development and/or dissemination of resistance in different compartments of the environment $[9,13]$.

Besides the risk of favoring microbial antibiotic resistance, antibiotic residues can be absorbed by plants, interfering with physiological processes and causing potential ecotoxicological effects. In order to highlight the negative effects, numerous chronic and acute toxicity tests have been performed, which revealed the impact of antibiotics on photosynthesis (chloroplasts gene expression, and cell proliferation) and mitochondria (oxidative stress response in plants), probably explained by the bacterial origins of chloroplasts and mitochondria [14]. Also, the concentrations of antibiotics which are found in agricultural soils could delay germination or reduce biomass, and consequently may negatively affect yield in farmland fertilized with contaminated manure [15]. Moreover, antibiotic residues can alter the human microbiome and cause health disturbances, such as allergic reactions, chronic toxic effects after prolonged exposure, and disruption of digestive system functions $[1,3,16]$.

The first aim of this review was to explore the primary drivers associated with antibiotic occurrence in the environment such as increased antibiotic consumption and antibiotic discharge. As a second aim, a comprehensive analysis of the current knowledge regarding the behavior of antibiotic residues and the effects of environmental contamination was performed. Last but not least, an update of scientific and regulatory facts about environmental and human antibiotics risk assessment was presented.

\section{Antibiotic consumption and antibiotics occurrence into the environment}

Over the decades following the discovery of antibiotics, it has been observed that antibiotic use in human medicine, veterinary medicine and agriculture is linked to the contamination of the different compartments of the environment (e.g. surface water, groundwater, drinking water, municipal sewage, soil, vegetables, sludge) and consequently to the rise in antibiotic resistance and has negative ecological effects [17]. Furthermore, antibiotic use enriches antibiotic resistant bacteria or resistance genes, which could be transferred from the environment to humans. It is assumed that increased antibiotic consumption may cause failure of treatments in human medicine (infections caused by antibiotic resistant bacteria), increasing duration of illness, morbidity and mortality [18-21].
Recent reports show that in the EU, 33,000 people die every year due to infections with antibiotic-resistant bacteria, in $39 \%$ of the cases death being associated with infections with bacteria resistant to last-line antibiotics such as carbapenems and colistin [22]. The situation is similar in U.S., where each year 2.8 million people get an antibiotic resistant infection and more than 35,000 people die [23]. Unfortunately, antibiotic resistant infections have a huge cost for the economic and healthcare system. The cost increase is related to the fact that these infections require therapy with last line antibiotics, which are a lot more expensive than the first- and second-line antibiotic therapy. Also, the length of hospitalization of the patient with antibiotic resistant infections can be prolonged by 6.4 to 12.7 days. The economic burden caused by infections with antibiotic resistant bacteria is estimated in the $\mathrm{EU}$ at EUR 1.5 billion per year in healthcare costs and productivity losses and $\$ 55$ billion in the U.S. [24,25].

One of the recent exhaustive analyses of human antibiotic consumption, estimated that between 2000 and 2015, antibiotic consumption, expressed in defined daily doses (DDD) increased by $65 \%$, with a particular rapid increase of the last resort antibiotics such as glycylcyclines, oxazolidinones, carbapenems and polymyxins. Also, we could expect an increase up to $200 \%$ until 2030 , if no policy changes will be made [26]. It has been observed that unnecessary antibiotic use is related to patients, practitioners and healthcare systems issues (e.g. expectation that a physician visit will lead to antibiotic prescription, poor knowledge of microbiology, underuse of available guidelines, lack of availability of local guidelines or lack of access to diagnostic tools etc.). Also, numerous social and cultural factors drive the misuse of antibiotics and influence attitudes towards prescribing and use of antibiotics [27]. However, improved hygiene, sanitation, vaccination and access to diagnostic tools remain the main measures that should be implemented for a responsible and rational use of antibiotics [26]. Other important measures are to limit the use of broad spectrum antibiotics, critically important antibiotics and to prohibit the discharge of antibiotic waste into the environment $[20,28-30]$.

Improper disposal of antibiotics, for example from households which are flushing antibiotics down the toilet, could represent a significant factor in the antibiotics occurrence into the wastewater systems. A lack of proper medication disposal practices among patients and clinicians require targeted sessions of awareness about the effects of improper disposal on the environment $[31,32]$. The hospital effluents represent another important source of antibiotic residues pollution. For instance, a positive correlation was observed between the quantity of ciprofloxacin prescribed in hospital and antibiotic residue levels in the hospital wastewater [33,34].

The contribution of the release of antibiotics in the environment to the spread and maintenance of clinically 
relevant antibiotic resistance is correlated with the antibiotic consumption patterns [35,36]. A better understanding of this correlation between the occurrence of antibiotic resistance and the use of antibiotics, would help in the development of targeted interventions and policies to optimize and promote the prudent use of antibiotics [26,30,35,37]. Also, it can help to implement surveillance systems for assessing efficacy of policies and regulations adapted to each country's specific context $[20,39,40]$. Therefore, an important objective is to monitor consumption of antibiotics in order to provide data on trends of antibiotic resistance and to make correlations with antibiotic use [38].

Legislation has the role of clarifying the responsibilities of governments and other stakeholders in the fight against antibiotic resistance that includes antibiotic usage and discharge into environment (Figure 1). However, we should be aware that "regulations are important, but not necessarily easy to influence in all regions or countries" and "not always followed" but, specific actions would be useful in the environments considered of high risk [39]. A recent systematic review identified 17 different policy strategies to reduce human antibiotic use, but most of the policies have not actually been evaluated regarding their impact on antibiotic use [39]. It has been observed in 20 countries throughout the WHO European Region that a high level of specific regulations is significantly correlated with a lower antibiotic consumption [40].

Regarding, veterinary antibiotic consumption it has been observed that BRICS countries with increased antibiotic consumption have fewer regulations in veterinary antibiotic use $[3,41]$. Veterinary antibiotic consumption has reported a significant increase and was justified by providing benefits for animal health, welfare and food safety, such as prevention and treatment of animal diseases, protection of humans against zoonosis, improving efficiency of production with a reduced animal breeding area and economic benefits for consumers and producers $[4,42]$. The significant factors that contribute and influence the amount of antibiotics used are the level of biosecurity and farming practices, the education of veterinarians, farmers and governmental and industry policies $[37,43]$.

Bengtsson-Palme et al. [44] mentioned that prudent use of antibiotics in humans and animals could limit the selective pressure on resistant pathogens and control development of environmental resistance. Therefore, this could avoid the creation of settings that select, mobilize and allow persistence of resistance genes in bacterial communities and could reduce dispersal routes for resistant bacteria to the human microbiome. Also, more research must be done to decipher the effects of antibiotics on the development of bacterial resistance in the environment and consequentially the impact on public health.

The antibiotic discharges from the pharmaceutical industry release higher concentrations in specific locations at certain times than other pollution sources and can pose a significant ecological and public health concern. These situations are particular, because there is no metabolism phase involved, which leads to higher levels of antibiotics in the wastewater systems $[45,46]$. Moreover, the environmental risk assessment required in the registration procedure for new pharmaceuticals in Europe and USA does not take into account emissions from manufacturing [27]. Voluntarily, several pharmaceutical companies have committed themselves to reducing effluent concentrations from their factories waste waters. Towards this purpose, several leading pharmaceutical companies signed an antimicrobial-resistance roadmap having the environmental management of antibiotic-related production as a central objective theme [47].

Regarding the environmental contamination with pharmaceuticals, the European Commission has admitted that "pollution of waters and soils with pharmaceuticals is an emerging environmental issue and also a critical concern for public health", but there are no standards regulating discharges of antibiotics from different sources [32]. The growing awareness of the potential for antibiotic residues to damage aquatic organisms has led to the placement of some antibiotic compounds (amoxicillin and ciprofloxacin) on the European Union (EU)" Watch List" of emerging water pollutants in 2015, followed by the addition of a few more antibiotics (erythromycin, clarithromycin and azithromycin) to this list in 2018 [48].

At European level, but also globally, in regards to soil, underground waters and wastewaters contamination, there is an absence of strict regulations on how to monitor the antibiotic concentration in the environment, to investigate the environmental fate of these compounds and the transmission of monitoring data (data transmission network) and to assess the environmental risk of antibiotics. This legislative permissiveness and inexistence of specific regulations could be partially explained by the lack of consensus on safe environmental concentrations of antibiotic residues in terms of development of resistance and the lack of clear and robust scientific evidence on environmental pollution with drug residues $[47,49]$.

Unfortunately, at this moment, there is no standard experimental protocol for environmental analysis of antibiotics and their transformation products (metabolites or degradation products, depending on their source). The EEA (European Environment Agency) guideline provides regulations for determining products of biotransformation (metabolites). In order to carry out consistent assessments of studies within a regulatory framework, validated and harmonized methods and more realistic experimental scenarios are needed at international level [8]. The majority of studies targeting antibiotic residues analysis tend to use techniques such as LC-MS/MS with a trend to develop multi-analyte techniques. But most efforts are focused on the detection of parent compounds, while simultaneous analysis of transformation products are rarely reported. In 
this context, analytical techniques would be needed to allow structural elucidation and identification of transformation products [50,51].

Quantification of the antibiotic residues is critical in establishing the link between their presence in the environment and their biological effects and ecotoxicological assessment. Also, it is an essential tool in the monitoring and surveillance of antibiotic residues in the environmental matrices as a consequence of inadequate antibiotic use. Improving assays and subsequently assessments that address the risk to ecosystems and human health due to the presence of antibiotics in agro-ecosystems and wastewaters requires progress in analytical accuracy and sensitivity, improvements in sample preparation for different environmental matrices, and in development of screening and quantification methods. All these are critical for monitoring and understanding the fate of antibiotics in the environment (Figure 1) [50-52]. Küster et al. specify that in order to minimize the quantity of pharmaceuticals in the environment it is necessary to improve the existing legislation for pharmaceuticals, including antibiotics, to prioritize pharmaceuticals as environmental pollutants and to improve the availability and collection of data concerning this group of pollutants (Figure 1) [53,54].

\section{The behavior of antibiotic residues and their} effects on the environment

Antibiotics are considered to be "persistent or pseudo-persistent substances because their entry rate into the environment is higher than the elimination rate" and comprise heterogeneous compounds, with various functional groups, responsible for very different physicochemical properties and behaviors in the ecosystem [55]. Also, the presence of the antibiotic residues in the environment is dependent on the pharmacokinetic profile of antibiotics. There are different classes of antibiotics, such as antibiotics with poor bioavailability after oral administration, antibiotics administered parenterally and excreted into the gastro-intestinal tract and antibiotics used in collective treatments in animals. For example, some antibiotics such as tetracyclines, which in general have low oral bioavailability, could remain in gastro-intestinal tract and expose commensal microbiota for a longer period than the treatment period because of their unabsorbed fraction. Later, the unabsorbed fraction is excreted into the environment, where it could exert a biological activity [56,57].

The biological activity of antibiotics in different environmental matrices depends on their bioavailable fraction and interaction with environmental conditions such as $\mathrm{pH}$, organic carbon content, type of soil, water content and type of organism etc. Therefore, to provide information about the bioavailable fractions and their effects on the environment represents a necessity and a major challenge especially regarding analytical determinations. In this case, there could be a potential gap between analytical results obtained in the lab and the bioavailable fraction in the environment $[9,50,58,59]$.

Understanding antibiotic degradation in the environment is essential, given the fact that the impact of antibiotic residues on aquatic and terrestrial ecosystems is still not fully understood [60]. There are a number of mechanisms of antibiotic degradation in the environment, which can be biotic, i.e. biodegradation by bacteria and fungi (microbial degradation) and/or non-biotic: hydrolysis, photolysis, oxidation and reduction, depending on the physicochemical properties, environmental conditions (temperature, light etc.) $[8,9,60,61]$. Other processes such as volatilization, adsorption, non-extractable residue formation may also occur and contribute to the dissipation of the active compounds. Transformation is faster in aerobic conditions than in anaerobic conditions and elevated temperatures favour degradation of compounds and could influence the structure of the microbial community $[8,62]$.

In studies investigating the fate of chlortetracycline, oxytetracycline and metabolites during anaerobic digestion, it was observed that the concentrations of chlortetracycline and of the epimer 4-epi chlortetracycline decreased, but those of iso-chlortetracycline metabolite doubled as compared to the initial concentration, due to increased metabolite solubility. The oxytetracycline and metabolites were found in low concentrations due to matrix binding $[8,63]$.

Schlüsener et al. [64] carried out a study on the persistence of macrolides and determined the half-lives in soils, which varied from 5 days to more than 120 days. The study of mobility and sorption of tylosin in soils in a laboratory setup has shown that tylosin was mineralized or irreversibly bound to solid soil particles [65]. A photo-induced degradation study, under UV irradiation, investigated the half-life of parent compounds (azithromycin, erythromycin, tylosin) and their photodegradation products which ranged between $0.2 \mathrm{~min}$ $-200 \mathrm{~min}$. The authors, recommended UV irradiation as a suitable method to eliminate macrolides from waters [66].

Most of the fluoroquinolones have high chemical stability and are not easily degraded with increased temperature or by hydrolysis. Therefore, they are rapidly transferred from water into the soil and sediments $[67,68]$. Due to their persistence in the environment, it was observed that high level of ciprofloxacin $(25 \mu \mathrm{g} / \mathrm{L})$ and norfloxacin $(5 \mu \mathrm{g} / \mathrm{L})$ can modify bacterial strains of Salmonella typhimurium and can cause genotoxic effects on aquatic organisms $[33,69]$.

Penicillins and cephalosporins have a high susceptibility to hydrolysis, which could occur within several weeks in most surface waters and over several days in more alkaline systems [51,70,71]. Also, they have a reduced tendency of adsorption to soil components, 
but could form complexes with cations and accumulate in sewage sludge and sediments. This may explain the bacterial resistance to cephalosporins observed in sewage treatment plants [77].

Therefore, antibiotics with a high adsorption potential on soil tend to accumulate and persist in this matrix, whereas those having a lower adsorption potential are easily transported into the aquatic environment $[13,61,74]$. Moreover, degradation products can be generated. These products can further be transformed into bioactive compounds, stable and mobile in the environment, with potentially higher toxicity than their parent and having significant impact on living organisms and microbial communities [15].

Weather conditions, such as acid rain, could promote the retention of antibiotics onto the surface soil and thus may pose risks to plants, through their uptake from soil, or to soil microorganisms [75,76]. Opriș et al. [77] explored the effect of nine antibiotics on leaf photosynthesis and found that cephalosporins strongly inhibited net assimilation due to reduced somatic conductivity. Beta-lactams have been considered as less toxic, but they also affect the division of plastids in lower plants [14]. Also an inhibition of catalase activity in the adult brain of Danio rerio, a fish species used in ecotoxicity evaluation, was observed in case of exposures to high concentrations of amoxicillin (50-100 mg/L) [16].

For the fluoroquinolones, the current challenge is the role of their cumulative effects in the environmental risk assessment $[14,78,79]$. They were shown to interfere with photosynthetic pathways and cause morphological deformities in higher plants and strongly inhibit net assimilation due to reduced somatic conductivity [14,77]. Aristilde et al. [78] pointed out the need to consider sublethal molecular targets as potential phytotoxicity end points.

Tetracyclines have phytotoxic effects that can cause chromosomal aberrations and inhibit plant growth, reducing the content of photosynthetic chlorophyll and carotenoid pigments in plants. Oxytetracycline is bioconcentrated in some aquatic plants that are destined for human consumption and which have been previously fertilized with pig manure [16]. Also, it has been shown that chlortetracycline and tetracycline could induce DNA breakage and changes in the enzymatic activities (superoxide dismutase and catalase) of Eisenia fetida (earthworms) [80].

Regarding the negative impact of antibiotic residues on microbial community structure and function, there is enough evidence to show that at low concentrations they can favor the occurrence of the resistance in primary bacteria in the environment, which can be transferred to species associated with human infections $[13,81,82]$.

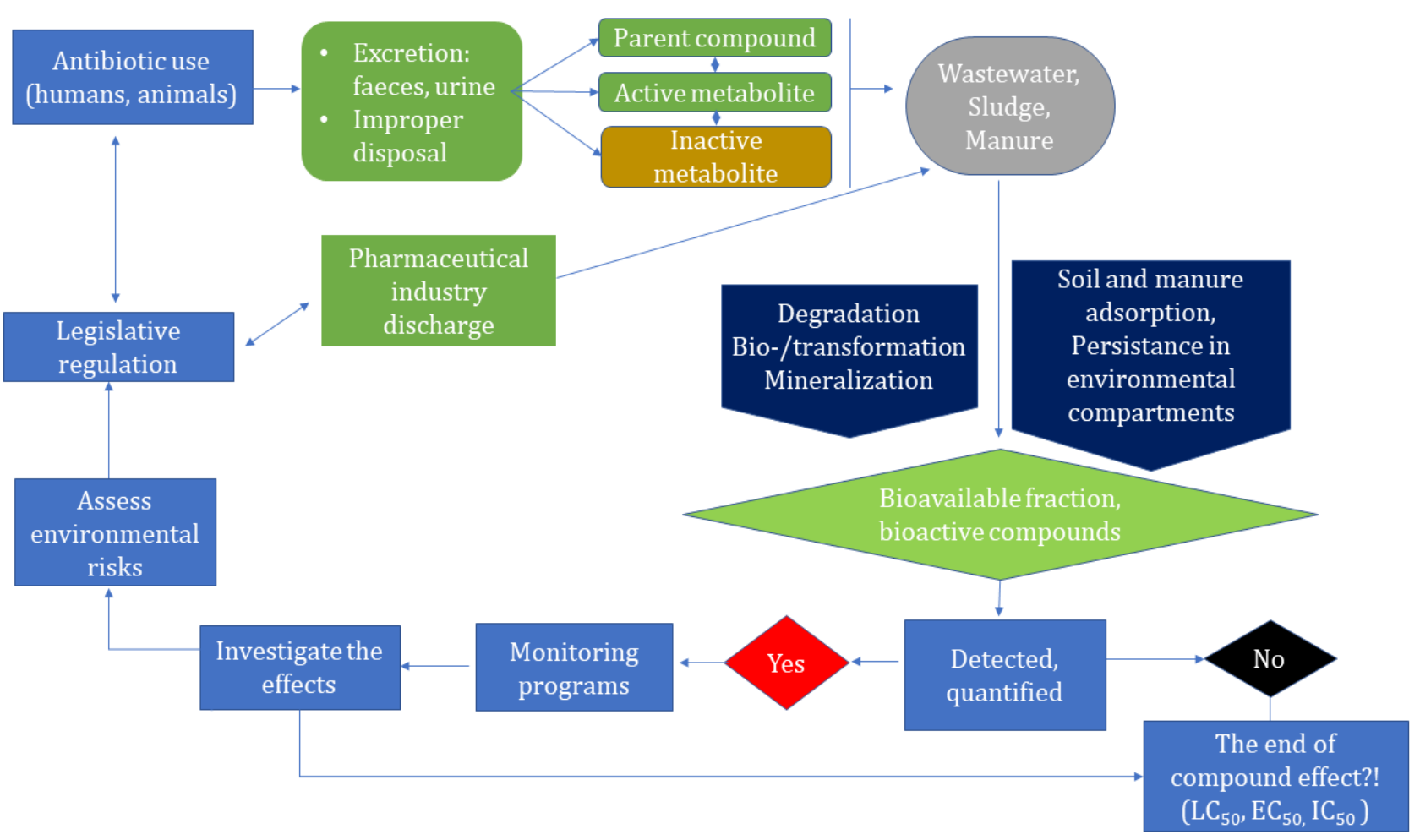

Figure 1. Antibiotics in the environment from discharge to analysis and environmental risk assessment. 
Figure 1 illustrates the previously described issues regarding the fate of antibiotics and their metabolites (active and inactive compounds) in the environment immediately after excretion and key steps for their monitoring and (re-)assessing environmental risk, which could guide the policy regulators. Increased antibiotic consumption leads to elevated concentrations of antibiotic residues and transformation products in the environment. The detection and quantification of the antibiotics occurred in the environment and compounds with potential biological activity represent a major step in elucidating the causal relationship between the presence of antibiotics in the environment and their effects on the ecosystem, including the major risk of developing antibiotic resistance. Also, monitoring and investigation of the effects could give a more solid scientific basis in order to change the way in which the environmental risk assessments are carried out.

\section{Ecotoxicological risk assessment of antibiotics}

One way of assessing the risks associated with the presence of antibiotics in the environment is based on the determination of risk coefficients (Figure 1). General toxicity indicators, such as $\mathrm{LC}_{50}, \mathrm{EC}_{50}$ and mean inhibitory concentration $\left(\mathrm{IC}_{50}\right)$, have been reported in numerous studies that have evaluated the effects of antibiotics on non-target sensitive organisms such as zebra fish, Daphnia, algae, mussels and other aquatic organisms [9]. But, in general, residues occur in the environment as mixtures and rarely in individual form. Consequently, additivity, synergism or antagonism could be expected in terms of biological effects of antibiotic mixtures. In case of binary antibiotic mixtures, the risk of environmental toxicity is higher by up to 50 $200 \%$ compared to the individual parent compounds alone assessed through simple concentration addition. Therefore, environmental risk assessment (ERA) should also include the toxicity of mixtures and the contribution of metabolites and degradation products $[50,83,84]$. Last but not least, it must be taken into account that the molecules introduced before 2006 were not characterized by the ERA and in the case of molecules introduced on the market after 2006, the information provided by the industry is incomplete [85].

To assess the ecotoxicological risk of antibiotic residues on microorganisms, the hazard quotient (HQ) and risk quotient (RQ) are usually calculated. The HQ is the ratio of the potential exposure to a substance (measured environmental concentration (MEC)) to the level at which no adverse effects are expected (predicted no effect concentration (PNEC)). The RQ is the ratio between expected environmental concentrations (PEC) and expected non-effect concentrations (PNEC). If the HQ is below 1, there is no risk, and if it exceeds 1 , it suggests a potential risk $[44,86]$. In the opinion of some environmental scientist, the PNEC needs to be taken just as a current indicator from a safety perspective [23]. However, a major concern is that the antibiotic selection pressure in the environment can accelerate the evolution and dissemination of antibioticresistant pathogens. At this point, there is no regulatory system for assessing such risk. The European Guideline on ERA for Medicinal Products for Human Use does not include the possibility of emergence and dissemination of environmental resistance after environmental contamination with antibiotics [87]. Bengtsson-Palme et al. [44] have estimated the upper limits of minimal selective concentrations (MSCs) for all common antibiotics, based on the fact that these concentrations should be a priori lower than those that completely inhibit growth.

G. Le Page et al. proposed a limit of $100 \mathrm{ng} / \mathrm{L}$ antibiotic discharge for the protection of the ecosystem function and for limiting the risk of antibiotic resistance development. Moreover, they emphasized that current ERA regulations are inadequate because of using species of cyanobacteria and that the activated sludge respiration inhibition test (which assesses the effects of antibiotics on the microorganisms in the activated sludge used in WWTP) does not set protection level for the environment. It is necessary to integrate clinically relevant bacteria and more species of environmentally relevant bacteria into the test systems of ERA, and also to assay the ability of resistance determinants to be transferred from treated wastewater, manure or other sources to commensal or pathogenic bacteria. Also, the integrated ERA could help to determine safe discharge concentrations for antibiotics and to protect environmental and human health [88-90].

Therefore, the scientific community proposes different measures which could be applied with a temporary character in order to limit the presence of antibiotics in the environment. The main measures for improving ERA could be to evaluate the toxicity of mixtures of antibiotics and the contribution of metabolites and degradation products and to estimate the upper limits of MSCs or to limit at $100 \mathrm{ng} / \mathrm{L}$ the antibiotics level of discharge. The use of clinically or environmentally relevant bacteria in the ERA test systems could provide more realistic results, allowing to establish safer discharge concentrations for antibiotics. It is also necessary to implement methods for monitoring antibiotic levels in the environment (Figure 1) in order to highlight the problem of antibiotic pollution and to improve in the end regulations regarding ERA.

\section{Concluding remarks}

The emergent issue of the occurrence of antibiotic residues and antibiotic resistance is a complex phenomenon which requires global approaches and efforts from governments, relevant organizations and stakeholders. Environmental antibiotic contamination should be diminished starting from regulating antibiotic consumption and ending with regulating ERA. 
Increased antibiotic consumption is directly responsible for the environmental contamination with antibiotics. Accurate policies on antibiotic use and discharge are absolutely required as the antibiotic misuse threatens the balance of ecosystems and human health. Therefore, to reduce and control antibiotic usage and antibiotic discharge into environment, legislative measures should target specific high-risk environments with elevated concentrations of antibiotics, such as WWTP of hospitals and of pharmaceutical industries, etc. Also, the scientific community proposed to impose limit values for the concentrations of antibiotics in the environment as a protective measure for environmental and human health. Moreover, the latest recommendations proposed an integrated risk assessment which should include both environmental and human health risks.

Occurrence of antibiotics in the environment is related to their chemical and pharmacokinetic properties, but also to the dynamic of environmental microbial communities, which could be altered and lead to antibiotic resistance bacterial mutations. An important support to regulate the presence of antibiotics in the environment is to elucidate the causal relationship between their presence and effects on the ecosystem. Consequently, the accurate detection and quantification of the antibiotics occurring in the environment and of compounds with potential biological activity would represent a major step in creating a scientific support base. The results obtained in available studies emphasize the necessity of monitoring and understanding the fate of antibiotics in the environment.

The benefits and need for the use of antibiotics cannot be ignored, but the effects of antibiotics in the environment must be taken into account, given their potential to maintain, cause and disseminate resistance, and also to exert a number of negative effects on the entire ecosystem. To improve knowledge regarding the impact of antibiotic residues on the environment, there is a need to take protective, timely measures to avoid latter irreversible consequences.

\section{References}

1. Ben Y, Fu C, Hu M, Liu L, Wong MH, Hung M, et al. Human health risk assessment of antibiotic resistance associated with antibiotic residues in the environment: A review. Environ Res. 2019;169:483-493.

2. Kinsella B, O’Mahony J, Malone E, Moloney M, Cantwell $\mathrm{H}$, Furey A, et al. Current trends in sample preparation for growth promoter and veterinary drug residue analysis. J Chromatogr A. 2009;1216:7977-8015.

3. Van Boeckel TP, Brower C, Gilbert M, Grenfell BT, Levin SA, Robinson TP, et al. Global trends in antimicrobial use in food animals. Proc Natl Acad Sci U S A. 2015;112:56495654.

4. Pruden A, Joakim Larsson DG, Amézquita A, Collignon P,
Brandt KK, Graham DW, et al. Management options for reducing the release of antibiotics and antibiotic resistance genes to the environment. Environ Health Perspect. 2013;121:878-885.

5. The Center for Disease Dynamics Economics \& Policy. Animal use and resistance. Available from: https:// resistancemap.cddep.org/AnimalUse.php.

6. Du L, Liu W. Occurrence, fate, and ecotoxicity of antibiotics in agro-ecosystems. A review. Agron Sustain Dev. 2012;32:309-327.

7. Andersson DI, Hughes D. Microbiological effects of sublethal levels of antibiotics. Nat Rev Microbiol. 2014;12(7):465478.

8. Wohde M, Berkner S, Junker T, Konradi S, Schwarz L, Düring RA. Occurrence and transformation of veterinary pharmaceuticals and biocides in manure: a literature review. Environ Sci Eur. 2016;28:23.

9. Jechalke S, Heuer H, Siemens J, Amelung W, Smalla K. Fate and effects of veterinary antibiotics in soil. Trends Microbiol. 2017;22:536-545.

10. Kuppusamy S, Kakarla D, Venkateswarlu K, Megharaj M, Yoon YE, Lee YB. Veterinary antibiotics (VAs) contamination as a global agro-ecological issue: A critical view. Agric Ecosyst Environ. 2018;257:47-59.

11. Jayalakshmi K, Paramasivam M, Sasikala M, Tamilam T, Sumithra A. Review on antibiotic residues in animal products and its impact on environments and human health. J Entomol Zool Stud JEZS. 2017;5:1446-1451.

12. Wang M, Shen W, Yan L, Wang XH, Xu H. Stepwise impact of urban wastewater treatment on the bacterial community structure, antibiotic contents, and prevalence of antimicrobial resistance. Environ Pollut. 2017;231(Pt 2):1578-1585.

13. Chee-Sanford JC, Krapac IJ, Yannarell AC, Mackie RI. Environmental Impacts of Antibiotic Use in the Animal Production Industry. Ecol Anim Heal Ecosyst Heal Sustain Agric 2. 2012;228-368.

14. Wang X, Ryu D, Houtkooper RH, Auwerx J. Antibiotic use and abuse: A threat to mitochondria and chloroplasts with impact on research, health, and environment. Bioessays. 2015;37:1045-1053.

15. Minden V, Deloy A, Volkert AM, Leonhardt SD, Pufal G. Antibiotics impact plant traits, even at small concentrations. AoB Plants. 2017;9:plx010.

16. Grossi Botelho R, Monteiro SH, Tornisielo VL. Chapter 5- Veterinary antibiotics in the environment. In: Emerging Pollutants in the Environment - Current and Further Implications. IntechOpen; 2012. pp. 135-152.

17. Hanna N, Sun P, Sun Q, Li X, Yang X, Ji X, et al. Presence of antibiotic residues in various environmental compartments of Shandong province in eastern China: Its potential for resistance development and ecological and human risk. Environ Int. 2018;114:131-142.

18. World Health Organisation. Monitoring global progress on addressing antimicrobial resistance: analysis report of the second round of results of AMR country self-assessment survey 2018. WHO, 2018. pp. 1-59. Available from : https://apps.who.int/iris/ 
bitstream/handle/10665/273128/9789241514422-eng. pdf? sequence $=1$ \&isAllowed $=\mathrm{y}$

19. Durso LM, Cook KL. Impacts of antibiotic use in agriculture: What are the benefits and risks? Curr Opin Microbiol. 2014;19:37-44.

20. Singer RS, Williams-Nguyen J. Human health impacts of antibiotic use in agriculture: A push for improved causal inference. Curr Opin Microbiol. 2014;19:1-8.

21. Merlin C. Reducing the Consumption of Antibiotics: Would That Be Enough to Slow Down the Dissemination of Resistances in the Downstream Environment? Front Microbiol. 2020;11:33.

22. ECDPC. 33000 people die every year due to infections with antibiotic-resistant bacteria. Available from: https://www. ecdc.europa.eu/en/news-events/33000-people-die-everyyear-due-infections-antibiotic-resistant-bacteria.

23. CDC. Antibiotic / Antimicrobial Resistance (AR / AMR). Available from: https://www.cdc.gov/drugresistance/index. html.

24. Mobarki N, Almerabi B, Hattan A. Antibiotic Resistance Crisis. Int J Med Dev Ctries. 2019;40:561-564.

25. European Commission. Antimicrobial resistance. Available from: https://ec.europa.eu/health/amr/antimicrobialresistance_en.

26 Klein EY, Van Boeckel TP, Martinez EM, Pant S, Gandra S, Levin SA, et al. Global increase and geographic convergence in antibiotic consumption between 2000 and 2015. Proc Natl Acad Sci U S A. 2018;115:E3463-E3470.

27. Office of the Chief Public Health Officer. Evidence Synthesis Summary: Social and Cultural Drivers of Antimicrobial Use. 2019; Available from: https://www.canada.ca/content/dam/ phac-aspc/documents/services/publications/drugs-healthproducts/social-cultural-drivers-antimicrobial-use/technicalreport-drivers-eng.pdf

28. Xiong W, Sun Y, Zeng Z. Antimicrobial use and antimicrobial resistance in food animals. Environ Sci Pollut Res Int. 2018;25:18377-18384

29. Hoelzer K, Wong N, Thomas J, Talkington K, Jungman E, Coukell A. Antimicrobial drug use in food-producing animals and associated human health risks: what , and how strong, is the evidence ? BMC Vet Res. 2017;13:211.

30. Padiyara P, Inoue H, Sprenger M. Global Governance Mechanisms to Address Antimicrobial Resistance. Infect Dis Res Treat. (Auckl). 2018;11:1178633718767887.

31. Kinrys G, Gold AK, Worthington JJ, Nierenberg AA. Medication disposal practices: Increasing patient and clinician education on safe methods. J Int Med Res. 2018;46:927-939.

32. Executive Agency for Health and Consumers. Study on the environmental risks of medicinal products. Final Report. 2013. Available from: https://ec.europa.eu/health/sites/ health/files/files/environment/study_environment.pdf.

33. Diwan V, Tamhankar AJ, Khandal RK, Sen S, Aggarwal M, Marothi Y, et al. Antibiotics and antibiotic-resistant bacteria in waters associated with a hospital in Ujjain, India. BMC Public Health. 2010;414:1-10.

34. Lien LT, Hoa NQ, Chuc NT, Thoa NT, Phuc HD, Diwan V, et al. Antibiotics in wastewater of a rural and an urban hospital before and after wastewater treatment, and the relationship with antibiotic use-a one year study from Vietnam. Int $\mathbf{J}$ Environ Res Public Health. 2016;13:588.

35. Carvalho IT, Santos L. Antibiotics in the aquatic environments: A review of the European scenario. Environ Int. 2016;94:736-757.

36. Singer AC, Shaw H, Rhodes V, Hart A. Review of antimicrobial resistance in the environment and its relevance to environmental regulators. Front Microbiol. 2016;7:1728.

37. Carmo LP, Nielsen LR, Alban L, Müntener CR, SchüpbachRegula G, Magouras I. Comparison of Antimicrobial Consumption Patterns in the Swiss and Danish Cattle and Swine Production (2007-2013). Front Vet Sci. 2017;4:26.

38. Stratchounski L, Bedenkov A, Hryniewicz W, Krcmery V, Ludwig E, Semenov V. The usage of antibiotics in Russia and some countries in Eastern Europe. Int $\mathrm{J}$ Antimicrob Agents. 2001;18:283-286.

39. Van Katwyk SR, Grimshaw JM, Nkangu M, Nagi R, Mendelson M, Taljaard M, et al. Government policy interventions to reduce human antimicrobial use: A systematic review and evidence map. PLoS Med. 2019;16:e1002819.

40. Mueller T, Östergren PO. The correlation between regulatory conditions and antibiotic consumption within the WHO European Region. Health Policy. 2016;120:882-889.

41. Gelband H. Policies to Address Antibiotic Resistance in Low- and Middle-Income Countries. The Center For Disease Dynamics, Economics \& Policy, 2014. Available from: https://cddep.org/publications/policies_address_antibiotic resistance_low_and_middle_income_countries/

42. Carlet J, Pulcini C, Piddock LJ. Antibiotic resistance: a geopolitical issue. Clin Microbiol Infect. 2014;20:949-953.

43. Manyi-Loh C, Mamphweli S, Meyer E, Okoh A. Antibiotic use in agriculture and its consequential resistance in environmental sources: Potential public health implications. Molecules. 2018;23:795.

44. Bengtsson-Palme J, Larsson DG. Concentrations of antibiotics predicted to select for resistant bacteria: Proposed limits for environmental regulation. Environ Int. 2016;86:140-149.

45. Larsson DGJ. Pollution from drug manifacturing: review and perspectives. Philos Trans R Soc Lond B Biol Sci. 2014;369:20130571.

46. Bielen A, Šimatović A, Kosić-Vukšić J, Senta I, Ahel M, Babić S, et al. Negative environmental impacts of antibioticcontaminated effluents from pharmaceutical industries. Water Res. 2017;126:79-87.

47. EEA. Pharmaceuticals in the environment - Results of an EEA workshop. Annual Review of Environment and Resources. 2010.

48. European Commission. Updated-surface-water-watch-listadopted-commission. Available from: https://ec.europa.eu/ $\mathrm{jrc/en/science-update/updated-surface-water-watch-list-}$ adopted-commission

49. European Commission. Communication from the commission to the european parliament, the council and the european economic and social committee and the committee 
of the regions on the delivery of the european agenda on migration. Brussels, 2017. Available from: https://ec.europa. eu/home-affairs/sites/homeaffairs/files/what-we-do/policies/ european-agenda-migration/20170927_communication_on the_delivery_of_the_eam_en.pdf.

50. Aga DS, Lenczewski M, Snow D, Muurinen J, Sallach JB, Wallace JS. Challenges in the Measurement of Antibiotics and in Evaluating Their Impacts in Agroecosystems: A Critical Review. J Environ Qual. 2016;45:407-419.

51. Längin A, Alexy R, König A, Kümmerer K. Chemosphere Deactivation and transformation products in biodegradability testing of beta-lactams amoxicillin and piperacillin. Chemosphere. 2009;75:347-354.

52. NAAS (National Academy of Agricultural Sciences). Antibiotics in manure and soil-A grave threat to human and animal health. Available from: http://naasindia.org/ Policy\%20Papers/policy\%2043.pdf

53. Küster A, Adler N. Pharmaceuticals in the environment: scientific evidence of risk and its regulation. Philos Trans R Soc Lond B Biol Sci. 2014;369:20130587.

54. European Commission. Priority substances under the Water Framework Directive. Available from: https://ec.europa.eu/ environment/water/water-dangersub/pri_substances.htm.

55. Coman C. Antibiotic resistance : not only the clinician's problem. Danube News. 2016;18:34:2-5.

56. Toutain PL, Ferran AA, Bousquet-Melou A, Pelligand L, Lees P. Veterinary medicine needs new green antimicrobial drugs. Front Microbiol. 2016;7:1196.

57. Committee for Medicinal Products for Veterinary Use (CVMP). Reflection paper on antimicrobials in the environment. 2018;44:1-50. Available from: www.ema. europa.eu/contact

58. Kumar RR, Lee JT, Cho JY. Fate, occurrence, and toxicity of veterinary antibiotics in environment. J Korean Soc Appl Biol Chem. 2012;55:701-709.

59. Subbiah M, Mitchell SM, Ullman JL, Call DR. $\beta$-lactams and Florfenicol Antibiotics Remain Bioactive in Soils While Ciprofloxacin, Neomycin, and Tetracycline Are Neutralized. Appl Environ Microbiol. 2011;77:7255-7260.

60. Kümmerer K. Antibiotics in the aquatic environment - a review - part I. Chemosphere. 2009;75:417-434.

61. Chang PH, Jiang WT, Li Z, Jean JS, Kuo C-Y. Antibiotic tetracycline in the environments - A review. Res Rev J Pharm Anal. 2015;4:86-111.

62. Boxall ABA, Rudd MA, Brooks BW, Caldwell DJ, Choi $\mathrm{K}$, Hickmann S, et al. Pharmaceuticals and personal care products in the environment: what are the big questions? Environ Health Perspect. 2012;120:1221-1229.

63. Arikan OA. The fate of chlortetracycline during the anaerobic digestion of manure from medicated calves. In: Gökçekus H, Türker U, LaMoreaux J (eds). Survival and Sustainability Environmental Earth Sciences Springer, Berlin, Heidelberg. 2010. pp. 1087-1096.

64. Schlüsener MP, Bester K. Persistence of antibiotics such as macrolides, tiamulin and salinomycin in soil. Environ Pollut. 2006;143:565-571.

65. $\mathrm{Hu} \mathrm{D}$, Coats JR. Laboratory evaluation of mobility and sorption for the veterinary antibiotic, tylosin, in agricultural soils. J Environ Monit. 2009;11:1634-1638.

66. Voigt M, Jaeger M. On the photodegradation of azithromycin, erythromycin and tylosin and their transformation products A kinetic study. Sustain Chem Pharm. 2017;5:131-140.

67. Frade VMF, Dias M, Teixeira ACSC, Palma MSA. Environmental contamination by fluoroquinolones. Brazilian J Pharm Sci. 2014;50:41-54.

68. Sturini M, Speltini A, Maraschi F, Profumo A, Pretali L, Fasani E, et al. Sunlight-induced degradation of soil-adsorbed veterinary antimicrobials Marbofloxacin and Enrofloxacin. Chemosphere. 2012;86:130-137.

69. Hartmann A, Golet EM, Gartiser S, Alder AC, Koller T, Widmer RM. Primary DNA damage but not mutagenicity correlates with ciprofloxacin concentrations in German hospital wastewaters. Arch Environ Contam Toxicol. 1999;36:115-119.

70. Li B, Zhang T. Biodegradation and adsorption of antibiotics in the activated sludge process. Environ Sci Technol. 2010;44:3468-3473.

71. Almeida A, Duarte S, Nunes R, Rocha H, Pena A, Meisel L. Human and Veterinary Antibiotics Used in Portugal - A Ranking for Ecosurveillance. Toxics. 2014;2:188-225.

72. Benassi FO, Vergara M, von Specht MH, García MA, Quiroga MI, Pucciarelli AB, et al. Beta-lactam antibiotic sensitivity in Aeromonas spp. of clinical, animal, and environmental origin. Rev Argent Microbiol 2001;33:47-51.

73. Kümmerer K. Resistance in the environment. J Antimicrob Chemother. 2004;54:311-20.

74. Cheng W, Li J, Wu Y, Xu L, Su C, Qian Y, et al. Behavior of antibiotics and antibiotic resistance genes in eco-agricultural system: A case study. J Hazard Mater. 2016;304:18-25.

75. Pan M, Chu LM. Leaching behavior of veterinary antibiotics in animal manure-applied soils. Sci Total Environ. 2017;579:466-473.

76. Solliec M, Roy-Lachapelle A, Gasser M-O, Coté C, Généreux $M$, Sauvé $S$. Fractionation and analysis of veterinary antibiotics and their related degradation products in agricultural soils and drainage waters following swine manure amendment. Sci Total Environ. 2016;543(Pt A):524535.

77. Opriş O, Copaciu F, Soran ML, Ristoiu D, Niinemets Ü, Copolovici L. Influence of nine antibiotics on key secondary metabolites and physiological characteristics in Triticum aestivum: Leaf volatiles as a promising new tool to assess toxicity. Ecotoxicol Environ Saf. 2013;87:70-79.

78. Aristilde L, Melis A, Sposito G. Inhibition of photosynthesis by a fluoroquinolone antibiotic. Environ Sci Technol. 2010;44:1444-1450.

79. Janusch F, Scherz G, Mohring SAI, Hamscher G. Determination of fluoroquinolones in chicken feces - A new liquid-liquid extraction method combined with LC-MS/MS. Environ Toxicol Pharmacol. 2014;38:792-799.

80. Dong L, Gao J, Xie X, Zhou Q. DNA damage and biochemical toxicity of antibiotics in soil on the earthworm Eisenia fetida. Chemosphere. 2012;89:44-51. 
81. Mojica E, Aga DS. Antibiotics Pollution in Soil and Water: Potential Ecological and Human Health Issues. Encycl Environ Heal. 2011;97-110.

82. Shao S, Hu Y, Cheng J, Chen Y. Research progress on distribution, migration, transformation of antibiotics and antibiotic resistance genes (ARGs) in aquatic environment. Crit Rev Biotechnol. 2018;38:1195-1208.

83. Marx C, Mühlbauer V, Krebs P, Kuehn V. Environmental risk assessment of antibiotics including synergistic and antagonistic combination effects. Sci Total Environ. 2015;524-525:269-279.

84. Danner MC, Robertson A, Behrends V, Reiss J. Science of the Total Environment Antibiotic pollution in surface fresh waters : Occurrence and effects. Sci Total Environ. 2019;664:793-804.

85. Ågerstrand $\mathrm{M}$, Berg $\mathrm{C}$, Björlenius $\mathrm{B}$, Breitholtz $\mathrm{M}$, Brunström B, Fick J, et al. Improving environmental risk assessment of human pharmaceuticals. Environ Sci Technol. 2015;49:5336-5345.
86. Carballo M, Aguayo S, González M, Esperon F, De La Torre A. Environmental assessment of tetracycline's residues detected in pig slurry and poultry manure. J Environ Prot. 2016;7:82-92.

87. European Medicines Agency. Environmental risk assessment of medicinal products for human use. Available from:https:// www.ema.europa.eu/en/environmental-risk-assessmentmedicinal-products-human-use.

88. Le Page G, Gunnarsson L, Snape J, Tyler CR. Integrating human and environmental health in antibiotic risk assessment: A critical analysis of protection goals, species sensitivity and antimicrobial resistance. Environ Int. 2017;109:155-169.

89. Berendonk TU, Manaia CM, Merlin C, Fatta-Kassinos D, Cytryn E, Walsh F, et al. Tackling antibiotic resistance: the environmental framework. Nat Rev Microbiol. 2015;13:310 317.

90. Felis E, Kalka J, Sochacki A, Kowalska K, Bajkacz S, Harnisz M, et al. Antimicrobial pharmaceuticals in the aquatic environment - occurrence and environmental implications. Eur J Pharmacol. 2020;866:172813. 